\title{
Apply a Piece-wise Peukert's Equation with Temperature Correction Factor to NiMH Battery State of Charge Estimation
}

\author{
Guoliang Wu ${ }^{1}$, Rengui Lu ${ }^{2}$, Chunbo Zhu ${ }^{3}$, and C. C. Chan ${ }^{4}$ \\ ${ }^{1}$ School of Electrical Engineering, Harbin Institute of Technology,wuguolianghit@gmail.com \\ ${ }^{2}$ School of Electrical Engineering, Harbin Institute of Technology, lurengui@hit.edu.cn \\ ${ }^{3}$ School of Electrical Engineering, Harbin Institute of Technology, zhuchunbo@hit.edu.cn \\ ${ }^{4}$ School of Electrical Engineering, Harbin Institute of Technology, ccchan@eee.hku.hk
}

\begin{abstract}
Battery state of charge is related with available capacity. Battery available capacity varies with temperature and discharge current. A good way to forecast available capacity is Peukert's equation. In order to verify the practicability of Peukert's equation at room temperature and low temperature, $1 / 3 C, 1 C, 2 C$, 3C rate discharge experiments were undertaken. The result indicates Peukert's equation is suitable for estimating available battery of $\mathrm{NiMH}$ battery in $25^{\circ} \mathrm{C}$. The result also indicates, at low temperatures, Peukert's equation is practical for NiMH battery at low current and unpractical in high current. Based on the result, a piece-wise Peukert's equation with Temperature Correction Factor to NiMH Battery State of Charge (SOC) estimation has been proposed. The proposed method improves the precision of SOC estimantion.
\end{abstract}

\section{Keywords}

state of charge, available capacity, NiMH battery, low temperature, piece-wise Peukert's equation

\section{INTRODUCTION}

State of charge (SOC) symbols the residual capacity of battery and it is written as the percent of residual capacity by nominal capacity. The estimation of SOC of NiMH battery is a key technology of energy management system in EV/HEV. The precise SOC monitors and controls the battery in order to maintain its optimum potential and extend its life, moreover it is benefit for controller to implement control strategy in HEV. Without precise SOC estimation, battery dies when it is overcharged or overdischarged [Jung et al., 2002].

The NiMH battery applies widely in electric vehicles, photovoltaic system and standby power of communication system. Its specific energy is much higher than lead acid battery, and the lead acid battery is substituted by the NiMH and the Li-ion battery in many fields. Though the specific energy of the Li-ion battery is higher than the NiMH battery, the Li-ion battery security problem is still to be solved that limits its development. Therefore, the NiMH battery is a good energy source in these fields. But battery available capacity is difficult to estimate. A famous method is Peukert's equation based on the Lead acid proposed in 1897 by Peukert [Peukert, 1897], which describes the relationship between battery available capacity and discharge current. The Peukert's equation is now widely accept- ed as a method of available capacity estimation for the Lead acid battery. Peukert's equation shows (1):

$C_{I}=K I^{(1-n)}$

where $\mathrm{n}$ and $\mathrm{k}$ are constant obtained by data of maximum discharge current and minimum current, and the calculated process is shown in appendix. Peukert's equation showed the available capacity decreases with the discharge current increasing [Bumby et al., 1985]. Peukert's equation is verified by lead acid [Peukert, 1897; Bumby, 1985; Chan, 2000; Vervaet, 2002; Song, 1998], which estimated the capacity with Peukert's equation. [Chan et al., 2000]'s opinion is that Peukert's equation is only suited for lead acid battery, but no experiment analysis and demonstration are shown. [Doerffel and Sharkh, 2006] analyzed the Li-ion battery, the results show Peukert's equation is good at estimation available capacity under constant current discharge, but is not suitable in variable current profile. Peukert's equation's practicability of the NiMH battery makes the authors carry out this experimental study. To the best of the authors' knowledge, no in-depth studies of the NiMH battery have been published.

Experiments and the discussion of practicability in $25{ }^{\circ} \mathrm{C}, 0{ }^{\circ} \mathrm{C},-12{ }^{\circ} \mathrm{C},-18{ }^{\circ} \mathrm{C}$ are in Section two. The proposed Piece-wise Peukert's equation is in Section Three. In Section four, the verification of proposed method for SOC estimation has been discussed. Conclusion is in Section five. 


\section{EXPERIMENTS AT ROOM AND LOW TEM- PERATURE}

\subsection{An Experiments apparatus}

A $27 \mathrm{Ah} / 1.2 \mathrm{~V} \mathrm{NiMH}$ battery was tested in these experiments. The battery test system for these experiments is shown in Figure 1, which includes the Arbin BT2000 Battery Test Instrument, data acquisition card, computer, and the NiMH battery. The battery voltage and current were measured by sensors of Arbin BT2000. Measured data were stored in computer. The specifications of the Arbin BT2000 battery test instrument are shown in Table 1. During the process of measuring the battery voltage and current, data were recorded in an excel file automatically. This monitor system can show current and voltage curves in real time. Before data acquisition, sample time and file path have to be set.

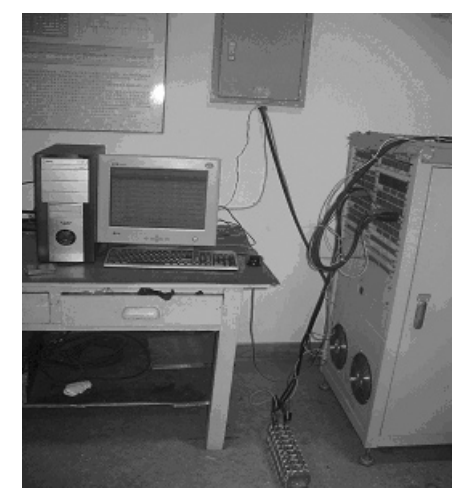

Fig. 1 The battery test system

Table 1 Specifications of the Arbin Bt2000 Battery Test Instrument

\begin{tabular}{|l|l|}
\hline Maximum discharge current & $100 \mathrm{~A}$ \\
\hline Maximum charge current & $100 \mathrm{~A}$ \\
\hline Voltage range during discharging & $0 \mathrm{~V}-18 \mathrm{~V}$ \\
\hline Voltage range during charging & $0 \mathrm{~V}-18 \mathrm{~V}$ \\
\hline Current measurement accuracy & $\pm 0.1 \%$ of Full Scale Range \\
\hline Voltage measurement accuracy & $\pm 0.1 \%$ of Full Scale Range \\
\hline
\end{tabular}

\subsection{Experiments at room temperature}

\subsubsection{Ah NiMH battery}

A $27 \mathrm{Ah}, 1.2 \mathrm{~V} \mathrm{NiMH}$ battery, had been used in this study at room temperature $25^{\circ} \mathrm{C}$. Constant current discharge experiments in $81 \mathrm{~A}, 54 \mathrm{~A}, 27 \mathrm{~A}, 9$ A were undertaken. Table 2 shows discharge times and available capacities under different currents. With the discharge current decreasing, the available capacity increases.

Peukert coefficients $\mathrm{n}$ and $\mathrm{K}$ are obtained using maximum current $81 \mathrm{~A}$ and minimum current $9 \mathrm{~A}$. The
Table $225{ }^{\circ} \mathrm{C}$ discharge times and available capacities under different currents

\begin{tabular}{|c|c|c|}
\hline $\begin{array}{c}\text { Discharge current } \\
{[\mathrm{A}]}\end{array}$ & $\begin{array}{c}\text { Discharge time } \\
{[\mathrm{h}]}\end{array}$ & $\begin{array}{c}\text { Available capacity } \\
{[\mathrm{Ah}]}\end{array}$ \\
\hline 81 & 0.2833 & 22.95 \\
\hline 54 & 0.4468 & 24.126 \\
\hline 27 & 0.9775 & 26.3906 \\
\hline 9 & 3.23 & 29.07 \\
\hline
\end{tabular}

coefficients $\mathrm{n}$ and $\mathrm{K}$ are shown below, Table 3 shows Calculated Capacities and Errors.

$C_{I}=K I^{(1-n)}=36.93 * I^{(1-1.1085)}, I \subseteq[9 \mathrm{~A}, 81 \mathrm{~A}]$

Table 3 Calculated capacities and errors at various currents

\begin{tabular}{|c|c|c|c|}
\hline $\begin{array}{c}\text { Discharge current } \\
{[\mathrm{A}]}\end{array}$ & $\begin{array}{c}\text { Available capacity } \\
{[\mathrm{Ah}]}\end{array}$ & $\begin{array}{c}\text { Calculated capacity } \\
{[\mathrm{Ah}]}\end{array}$ & $\begin{array}{c}\text { Error } \\
{[\%]}\end{array}$ \\
\hline 81 & 22.95 & 22.925 & 0.11 \\
\hline 54 & 24.126 & 23.956 & 0.704 \\
\hline 27 & 26.3906 & 25.8271 & 2.135 \\
\hline 9 & 29.07 & 29.0967 & 0.0009 \\
\hline
\end{tabular}

Peukert coefficient $\mathrm{n}$ range is 1 to 1.2 in NiMH battery at $25{ }^{\circ} \mathrm{C}$. The maximum error of calculated data is $2.5906 \%$. It is practical to apply Peukert's equation to estimate available capacity of The NiMH battery at room temperature $25^{\circ} \mathrm{C}$.

\subsection{Experiments at low temperature}

Battery available capacity is dependent with temperature, but temperature is not considered in traditional Peukert's equation. Therefore a research in-deep of Peukert's equation at low temperatures is undertaken in below. At three temperatures $0{ }^{\circ} \mathrm{C},-12{ }^{\circ} \mathrm{C},-18{ }^{\circ} \mathrm{C}$, experiments at $9 \mathrm{~A}, 27 \mathrm{~A}, 54 \mathrm{~A}, 81 \mathrm{~A}$ current discharge are undertaken.

Discharge times and available capacities under $1 / 3 \mathrm{C}$, $1 \mathrm{C}, 2 \mathrm{C}, 3 \mathrm{C}$ rate $(9 \mathrm{~A}, 27 \mathrm{~A}, 54 \mathrm{~A}, 81 \mathrm{~A})$ at $0{ }^{\circ} \mathrm{C}$ display in Table 4 . The available capacity decreases with temperature decreasing at the same current.

$C_{I}=K I^{(1-n)}=33.445^{*} I^{(1-1.128)}, I \subseteq[9 \mathrm{~A}, 81 \mathrm{~A}]$

Discharge times and available capacities under $1 / 3 \mathrm{C}$, $1 \mathrm{C}, 2 \mathrm{C}, 3 \mathrm{C}$ rate at $-12{ }^{\circ} \mathrm{C}$ display in Table 5. Peukert coefficient $\mathrm{n}$ under $-12{ }^{\circ} \mathrm{C}$ is shown in Table 6. Maximum current is $81 \mathrm{~A}$ and minimum current is $9 \mathrm{~A}$. The Peukert's equation requests the coefficient $\mathrm{n}$ is between 1 and 2, otherwise, the Peukert's equation loses 
Table $40{ }^{\circ} \mathrm{C}$ discharge times and available capacities under different currents

\begin{tabular}{|c|c|c|}
\hline $\begin{array}{c}\text { Discharge current } \\
{[\mathrm{A}]}\end{array}$ & $\begin{array}{c}\text { Discharge time } \\
{[\mathrm{h}]}\end{array}$ & $\begin{array}{c}\text { Available capacity } \\
{[\mathrm{Ah}]}\end{array}$ \\
\hline 81 & 0.234 & 18.966 \\
\hline 54 & 0.376 & 20.295 \\
\hline 27 & 0.847 & 22.883 \\
\hline 9 & 2.799 & 25.1960 \\
\hline
\end{tabular}

Table $5-12{ }^{\circ} \mathrm{C}$ discharge times and available capacities under different currents

\begin{tabular}{|c|c|c|}
\hline $\begin{array}{c}\text { Discharge current } \\
{[\mathrm{A}]}\end{array}$ & $\begin{array}{c}\text { Discharge time } \\
{[\mathrm{h}]}\end{array}$ & $\begin{array}{c}\text { Available capacity } \\
{[\mathrm{Ah}]}\end{array}$ \\
\hline 81 & 0.0038 & 0.3069 \\
\hline 54 & 0.247 & 13.3366 \\
\hline 27 & 0.579 & 15.633 \\
\hline 9 & 1.801 & 16.2126 \\
\hline
\end{tabular}

Table 6 Peukert coefficient $\mathrm{n}$ under $-12{ }^{\circ} \mathrm{C}$

\begin{tabular}{|c|c|}
\hline Max current and Min Current & Peukert coefficient $\mathrm{n}$ \\
\hline $81 \mathrm{~A}, 9 \mathrm{~A}$ & 2.8040 \\
\hline $54 \mathrm{~A}, 9 \mathrm{~A}$ & 1.1092 \\
\hline
\end{tabular}

its physical meanings. But coefficient $\mathrm{n}$ calculated by 81 A data and 9 A data is 2.8040, which is larger than 2. The available capacity of $81 \mathrm{~A}$ is $0.3069 \mathrm{Ah}$, which is far less than $22.95 \mathrm{Ah}$ at $25^{\circ} \mathrm{C}$. The result indicates Peukert's equation is not suitable for $81 \mathrm{~A}$ at $-12{ }^{\circ} \mathrm{C}$. Therefore, maximum current has to be selected again. $54 \mathrm{~A}$ is selected as a new maximum current. $\mathrm{n}$ calculated by $54 \mathrm{~A}$ data and $9 \mathrm{~A}$ data is 1.1092, which is between 1 and 2 .

$C_{I}=K I^{(1-n)}=19.2474 * I^{(1-1.1092)}, I \subseteq[9 \mathrm{~A}, 54 \mathrm{~A}]$

Discharge times and available capacities under $1 / 3 \mathrm{C}$, $1 \mathrm{C}, 2 \mathrm{C}, 3 \mathrm{C}$ rate $(9 \mathrm{~A}, 27 \mathrm{~A}, 54 \mathrm{~A}, 81 \mathrm{~A})$ at $-18^{\circ} \mathrm{C}$ display in Table 7. Peukert coefficient $\mathrm{n}$ under $-18^{\circ} \mathrm{C}$ is shown in Table 8 . Coefficient $\mathrm{n}$ calculated by maximum current $81 \mathrm{~A}$ data and minimum current 9A data is 4.7569 , which is larger than 2. Coefficient $n$ calculated by maximum current $54 \mathrm{~A}$ data and minimum current $60 \mathrm{~A}$ data is 3.3798 , which is also larger than 2 . The available capacity of $81 \mathrm{~A}$ is $0.00316 \mathrm{Ah}$, which is far less than $22.95 \mathrm{Ah}$ at $25^{\circ} \mathrm{C}$. The available capacity of $54 \mathrm{~A}$ is $0.1716 \mathrm{Ah}$, which is also far less than 22.95 $\mathrm{Ah}$ at $25^{\circ} \mathrm{C}$. The data indicate Peukert's equation is
Table $7-18{ }^{\circ} \mathrm{C}$ Discharge times and available capacities under different currents

\begin{tabular}{|c|c|c|}
\hline $\begin{array}{c}\text { Discharge current } \\
{[\mathrm{A}]}\end{array}$ & $\begin{array}{c}\text { Discharge time } \\
{[\mathrm{h}]}\end{array}$ & $\begin{array}{c}\text { Available capacity } \\
{[\mathrm{Ah}]}\end{array}$ \\
\hline 81 & 0.00004 & 0.00316 \\
\hline 54 & 0.0032 & 0.1716 \\
\hline 27 & 0.415 & 11.15 \\
\hline 9 & 1.355 & 12.12 \\
\hline
\end{tabular}

Table 8 Peukert coefficient $\mathrm{n}$ under $-18{ }^{\circ} \mathrm{C}$

\begin{tabular}{|c|c|}
\hline Max current and Min Current & Peukert coefficient $\mathrm{n}$ \\
\hline $81 \mathrm{~A}, 9 \mathrm{~A}$ & 4.7569 \\
\hline $54 \mathrm{~A}, 9 \mathrm{~A}$ & 3.3798 \\
\hline $27 \mathrm{~A}, 9 \mathrm{~A}$ & 1.06723 \\
\hline
\end{tabular}

not suitable for $81 \mathrm{~A}$ and $54 \mathrm{~A}$ at $-18^{\circ} \mathrm{C}$. Coefficient $\mathrm{n}$ calculated by $27 \mathrm{~A}$ data and $9 \mathrm{~A}$ data is 1.06723 , which is between 1 and 2 .

$C_{I}=K I^{(1-n)}=13.99 * I^{(1-1.067)}, I \subseteq[9 \mathrm{~A}, 27 \mathrm{~A}]$

All data of available capacity in $9 \mathrm{~A}, 27 \mathrm{~A}, 54 \mathrm{~A}, 81 \mathrm{~A}$ at $25{ }^{\circ} \mathrm{C}, 0{ }^{\circ} \mathrm{C},-12{ }^{\circ} \mathrm{C},-18{ }^{\circ} \mathrm{C}$ are shown in Figure 2 , which indicates that the available capacity decreases with temperature decreasing in the same current and the available capacity decreases with current improving at the same temperature. The available capacity of $81 \mathrm{~A}$ at $-18^{\circ} \mathrm{C}$ is only $0.00316 \mathrm{Ah}$.

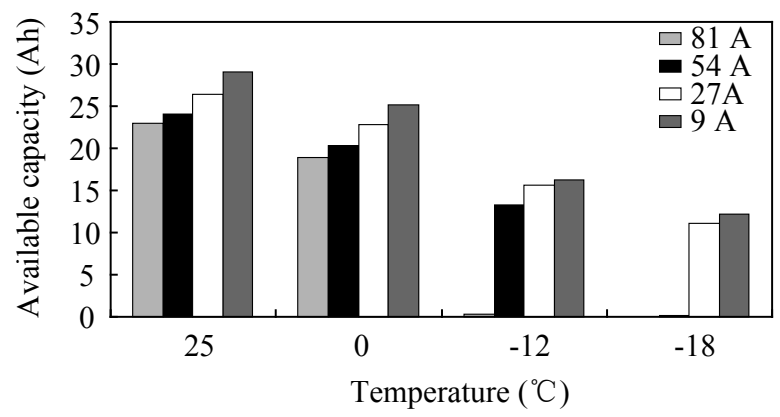

Fig. 2 The available capacity in 9 A, 27 A, 54 A, 81 A at $25{ }^{\circ} \mathrm{C}, 0{ }^{\circ} \mathrm{C},-12{ }^{\circ} \mathrm{C},-18{ }^{\circ} \mathrm{C}$

\section{THE PIECE-WISE PEUKERT'S EQUATION WITH TEMPERATURE CORRECTION FAC- TOR}

According the result talked above, the choice of Peukert's coefficient is not only related with discharge current, but also related with temperature. According to the value of coefficient $\mathrm{n}$ and $\mathrm{K}$ at four different 


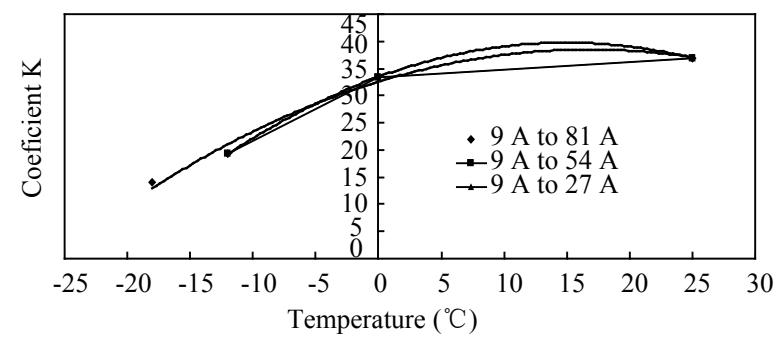

Fig. 3 The relationship of temperature and $\mathrm{K}$ of three current fields

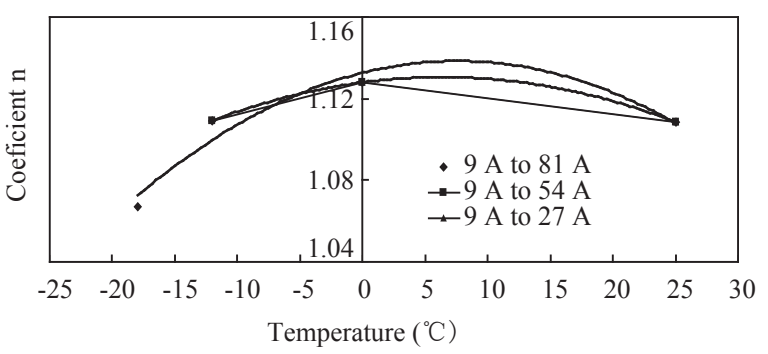

Fig. 4 The relationship of temperature and $n$

temperature, a relation curve of $\mathrm{n}$ and temperature has been set with least square fitting, which is shown in Figure 3. In the same way, a relation curve of $\mathrm{K}$ and temperature also has been set with least square fitting, which is shown in Figure 4. Based on the two relation curves talked above, a formula of $\mathrm{n}$ and temperature, which is shown in formula (6), and a formula of $\mathrm{K}$ and temperature, which is shown in formula (7) are built. A piece-wise Peukert's equation with temperature correction factor has been set, which is shown in formula (8).

$K= \begin{cases}(-0.0212) \times T^{2}+0.708 \times T+32.568 & 9 \mathrm{~A} \leq I \leq 27 \mathrm{~A},-18 \leq T \leq 25 \\ (-0.0282) \times T^{2}+0.8446 \times T+33.445 & 27 \mathrm{~A}<I \leq 54 \mathrm{~A},-12 \leq T \leq 25 \\ -0.1394 \times T+33.445 & 54 \mathrm{~A}<I \leq 81 \mathrm{~A}, 0 \leq T \leq 25\end{cases}$

$n= \begin{cases}(-0.0001) \times T^{2}+0.0015 \times T+1.1327 & 9 \mathrm{~A} \leq I \leq 27 \mathrm{~A},-18 \leq T \leq 25 \\ (-0.00006) \times T^{2}+0.0008 \times T+1.128 & 27 \mathrm{~A}<I \leq 54 \mathrm{~A},-12 \leq T \leq 25 \\ (-0.0008) \times T+1.128 & 54 \mathrm{~A}<I \leq 817 \mathrm{~A}, 0 \leq T \leq 25\end{cases}$

According to the piece-wise Peukert's equation with temperature correction factor, available capcity under any low temperature can be estimated. The piece-wise Peukert's equation with temperature correction factor:

$C_{l, T}=K I^{(1-n)}= \begin{cases}\left((-0.0212) \times T^{2}+0.708 \times T+32.568\right) \\ \times I^{\left(1-\left(-(-0.0000) \times T^{2}+0.0015 \times T+1.1327\right)\right)} & 9 \mathrm{~A} \leq I \leq 27 \mathrm{~A},-18 \leq T \leq 25 \\ \left((-0.0282) \times T^{2}+0.8446 \times T+33.445\right) & \\ \times I^{\left(1-\left(-(-0.000000) \times T^{2}+0.0008 \times T+1.1 .28\right)\right)} & 27 \mathrm{~A}<I \leq 54 \mathrm{~A},-12 \leq T \leq 25 \\ (0.1394 \times T+33.445) & 54 \mathrm{~A}<I \leq 81 \mathrm{~A}, 0 \leq T \leq 25 \\ \times I^{(1-(-(-0.0000) \times T+1.128))}\end{cases}$

(8)

\section{SOC ESTIMATION BASED ON THE PIECE- WISE PEUKERT'S EQUATION WITH TEM- PERATURE CORRECTION FACTOR}

\subsection{SOC loss mode of low temperature}

Based on the piece-wise Peukert's equation with temperature correction factor, a capacity loss model and a SOC loss model model of low temperature are proposed. The capacity loss model of low temperature is shown in formula (9). The SOC loss model of low temperature is shown in in formula (10).

The capacity loss model of low temperature

$$
\begin{aligned}
C_{T_{-} \text {loss }}= & C_{n o \min a l}-\left(-0.0212 \times T^{2}+0.708 \times T+32.568\right) \\
& \times I^{\left(1-\left((-0.0001) \times T^{2}+0.0015 \times T+1.1327\right)\right)}
\end{aligned}
$$

The SOC loss model model of low temperature

$$
\begin{aligned}
& S_{T_{-} \text {loss }}=C_{T_{-} \text {loss }} / C_{n o \text { min al }} \\
& =\left(C_{\text {no min al }}-\left(-0.0212 \times T^{2}+0.708 \times T+32.568\right) \times\right. \\
& \left.I^{\left(1-\left((-0.0001) \times T^{2}+0.0015 \times T+1.1327\right)\right)}\right) / C_{\text {no min al }}
\end{aligned}
$$

\subsection{An improved SOC estimation method}

According to the SOC loss model of low temperature, an improved SOC estimation method has been proposed, which is shown in formula (11).

$\operatorname{SOC}(t)=\operatorname{SOC}(0)-\int_{0}^{\mathrm{t}} 100 \frac{\eta_{\mathrm{I}, \mathrm{T}} I}{C_{\text {no min al }}}-\mathrm{S} T_{\text {loss }}$

A $1 / 3 \mathrm{C}$ rate current discharge experiment at $-18{ }^{\circ} \mathrm{C}$ is used to verify the SOC estimation precision of the improved SOC estimation method, which is shown in Figure 5. In the first step, NiMH battery is charged to full. In the second, NiMH battery was put into icebox for 12 hours. In the third step, 1/3 $\mathrm{C}$ rate current discharge experiment was undertaken under $-18^{\circ} \mathrm{C}$.

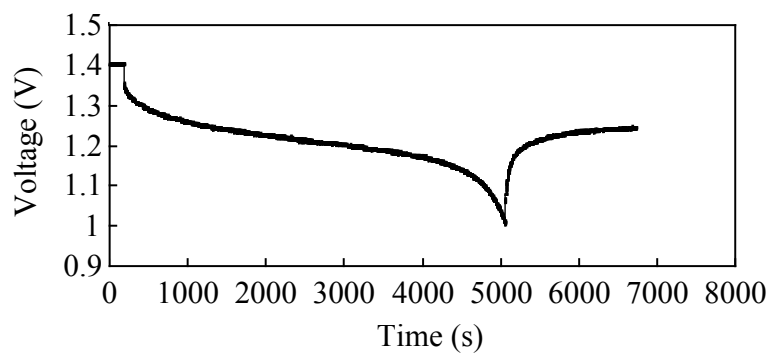

Fig. 5 Discharge experiment under $-18^{\circ} \mathrm{C}$

Comparision real SOC and estimated SOC, which is shown in Figure 6. the error of proposed method is 9 $\%$, the error of traditional Amper-hour method is $58 \%$. The experiment result shows that the improved SOC 


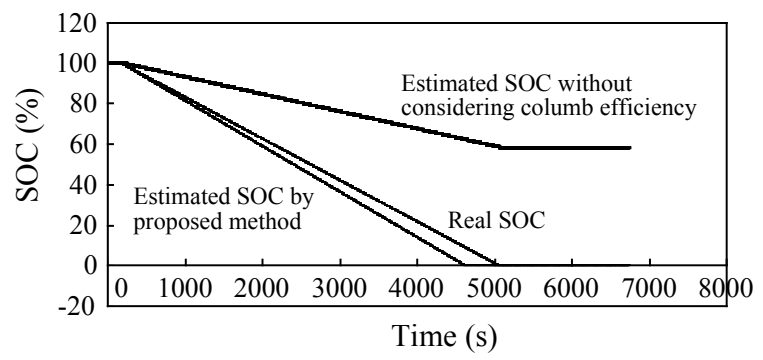

Fig. 6 Comparision of real and estimated SOC with discharge experiment at $1 / 3 \mathrm{C}$ rate under $-18{ }^{\circ} \mathrm{C}$

estimation method improves the precision of SOC estimation because it considers that battery available capacity decreases with temperature decreasing.

\section{CONCLUSION}

(1) Verifying the practicality of applying Peukert's equation to estimate available capacity of $\mathrm{NiMH}$ battery.

(2) A piece-wise Peukert's equation with temperature correction factor is proposed.

(3) A SOC loss model at low temperature is proposed.

(4) The improved SOC estimation method is proposed which improves the precision of SOC estimation.

\section{References}

Bumby, J. R., P. H. Clarke, and I. Forster, Computer modeling of the automotive energy requirements for internal combustion engine and battery electricpowered vehicle, IEE Proceedings, Vol. 132, No. 5, 265-279, 1985.

Chan, C. C., E. W. C. Lo, and S. Weixiang, The available capacity computation model based on artificial neural network for lead-acid battery in electric vehicles, Journal of Power Sources, Vol. 87, No. 1-2, 201-204, 2000.

Doerffel, D., and S. A. Sharkh, A critical review of using the Peukert equation for determining the remaining capacity of lead-acid and lithium-ion battery, Journal of Power Sources, Vol. 155, No. 2, 395-400, 2006.

Jung D.Y., B. H. Lee, and S. W. Kim, Development of battery management system for nickel-metal hydride batteries in electric vehicle applications, Journal Of Power Sources, Vol. 109, No. 1, 1-10, 2002.

Song, S. K., State-of-charge measuring method using multilevel Peukert equation, Journal of Power Sources, Vol. 70, No. 1, 157, 1998.

Vervaet, A., and D. Baert, The lead-acid battery: semiconducting properties and Peukert's law, Electrochim Acta, Vol. 47, No. 20, 3297-3302, 2002.
W. Peukert, An equation for relating capacity to discharge rate, Electrotech, Vol. Z.18, 287-288, 1897.

(Received March 20, 2010; accepted November 4, 2010)

\section{Appendix}

$n=\frac{\lg \left(t_{2} / t_{1}\right)}{\lg \left(I_{1} / I_{2}\right)}$

$K=I_{1}^{n} t_{1}=I_{2}^{n} t_{2}$

Where $I$-Discharge current

$I_{1}$ - Maximum discharge current

$I_{2}$ - Minimum discharge current

$t_{1}$ - discharge time in $I_{1}$

$t_{2}$ - discharge time in $I_{2}$ 